Divanorkesteret er av mange både feiret og romantisert, men samtidig preget av en rekke spenningsfelter i konstant forhandling. Denne artikkelen tar for seg to av forhandlingsområdene som påvirker konflikttransformasjonen.

\title{
Forhandlinger $\mathbf{i}$ Divanorkesteret
}

Solveig Riiser har mastergrad i musikkvitenskap med oppgaven «Negotiating the Divan. A study of the West-Eastern Divan Orchestra». 
assosieres ofte med Goethe, og orkesteret har hentet navnet sitt fra Goethes kjente diktsamling «West-Östlicher Diwan».

\section{Spenningsfelt og forhandling}

Sommeren 2008 var jeg tilstede på Divanorkesterets workshop i den lille byen Pilas utenfor Sevilla i Spania. Gjennom I2 intense dager preget av orkesterprøver, gruppeprøver og diskusjoner om kunst, litteratur, politikk og musikk snakket jeg med majoriteten av de I2I musikerne som utgjorde Divanorkesteret anno 2008. Under mitt feltarbeid fant jeg at Divanorkesteret er preget av en rekke spenningsfelter, både knyttet til verdi/ideologi og mellom orkesterets lederskap/dirigent på den ene siden og musikere på den andre. I denne artikkelen vil jeg ta for meg to

TEKST: Solveig Riiser

UNGDOMSORKESTRET West-Eastern Divan Orchestra (heretter Divanorkesteret) ble etablert av den verdensberømte argentinskisraelske dirigenten Daniel Barenboim (I942-) og den palestinske litteraturprofessoren og kritikeren Edward Said (I935-2003) i I999. «Musikk gjør dette prosjektet mulig», skriver de, «fordi musikk ikke inneholder de samme begrensningene som ord gjør. Musikken lærer oss at alt har en parallell eller en motsetning». ${ }^{\mathrm{I}}$ Med utgangspunkt i denne ideen samles over hundre musikere hvert år til workshop og påfølgende turné. Orkesteret består av unge musikere fra Libanon, Syria, Israel, Palestina, Egypt, Jordan, Tyrkia og Iran, foruten spanske musikere. ${ }^{2}$

Divanorkesteret hadde sin første samling i Weimar, Tyskland, da denne var europeisk kulturhovedstad i I999. Weimar spenningsfelt: nasjonalisme versus kosmopolitisme og empowerment versus kultivering, med utgangspunkt i spørsmålet «Hva slags forhandlinger foregår i Divanorkesteret?». ${ }^{3}$ Presentert på denne måten er Divanorkesteret et interessant etnografisk materiale som belyser konflikttransformeringsprosjekter.

Spenningsfeltene må ses i sammenheng. Empowerment- eller kultiveringsprosessene er det som gjør identitetsskaping og relasjonsbygging mulig, det her verdigrunnlaget eller ideologien - nasjonalisme versus kosmopolitisme - defineres. Begge spenningsfelter er også preget av at både musikk og samtale brukes som dialogverktøy. I sum kan vi snakke om en rekke forhandlinger. Begrepet refererer her til det å «forsøke å finne en avtale eller et kompromiss gjennom diskusjon», ${ }^{4}$ og brukes med referanse til både den verbale aktiviteten «forhandling», og til musikalsk aktivitet. ${ }^{5}$ Gjennomgående er vi stilt oven- 
for problemstillinger knyttet til de interne maktrelasjonene i orkesteret. Maktbegrepet ses i lys av Bourdieus teorier, som tillater at vi plasserer kultur i forhold til et større sosialt maskineri som opprettholder sosiale hierarkier. ${ }^{6}$

Identitet brukes som utgangspunkt for en presentasjon av spenningsfeltet nasjonalisme/kosmopolitisme. Divanorkesteret er både en relasjonsbyggende og en identitetsskapende arena for musikerne, men

\section{Divanorkesteret er et makthierarki med den gjenlevende grunnleggeren og dirigenten på toppen.}

mens Barenboim og Said legger kosmopolitiske verdier til grunn for denne utviklingen, ser det ut til at nasjonalisme er musikernes grunnlag. Kosmopolitisme forstås her som et alternativ til nasjonalistisk sosial- og samfunnsorganisering.? Orkesterets grunnleggere kan begge omtales som kosmopolitter (eksempler på dette senere), og man kan forstå flere av deres bøker som beretninger om kosmopolitisme som identitetsmarkører. ${ }^{8}$ På den annen side er orkestermusikernes utgangspunkt for dialogen i Divanorkesteret i stor grad hentet fra det nasjonale: De er Divanmedlemmer i kraft av deres nasjonale tilhørighet, og de fokuserer på dialogen mellom arabere og israelere. ${ }^{9}$

Det nasjonale forstås her som den primære områdeinndelingen som, hvis vi følger Edensors teorier, er en sterk identitetsmarkør - dog kompleks og mangesidet. ${ }^{\text {. }}$ Ifølge Ruud skaper vi vår identitet gjennom de narrativene vi forteller om oss selv. ${ }^{\text {II }}$
Identitet forstås følgelig her som et vedvarende refleksivt prosjekt som foregår innenfor en bestemt historisk, sosial og kulturell kontekst. Denne prosessen er ikke verdieller maktnøytral: Identitetspolitikk må fortolkes i lys av de maktrelasjoner som utgjør hierarkiet mellom grupper. ${ }^{12}$ Herfra er det enkelt å slutte at det i Divanorkesteret er et makthierarki der orkesterets gjenlevende grunnlegger og dirigent er på toppen. Som Attali påpeker er ikke dirigenten bare den legitime og rasjonelle organisereren av en produksjon hvis størrelse krever koordinering, han har også enorm makt over orkesteret som et samfunn. ${ }^{\text {13 }}$

Spenningsfeltet mellom empowerment og kultivering er beskrivende i hvordan orkesterhierarkiet påvirker de interne prosessene. Fellesnevneren for begge prosessene er utvikling, og begrepene empowerment og kultivering er primært brukt som et metodisk begrepsapparat. Det springende punkt er hvordan musikerne på den ene siden og orkesterets dirigent på den andre tillater politikkens eksistens i orkesteret. Empowermentprosessen gjør musikerne i stand til å delta i diskusjoner preget av gjensidig toleranse og åpenhet, der også politiske tema er velkomne. Empowerment er basert på den engelske definisjonen «Give someone the authority or power to do something», og henviser til begreper som involvering, selvbestemmelse og deltakelse, jamfør (musikk)terapeutisk teori. ${ }^{\text {I4 }}$ Empowermentprosessens motsetning er kultiveringsprosessen, definert av Barenboim og Said, og opprettholdt av Barenboim-Said Foundation (administrativt ansvarlig for Divanorkesteret, heretter Foundation) og Barenboim. I motsetning til empowermentprosessen handler denne om en utvikling der alle politiske temaer utelates. 
Prosessene vil bli grundigere definert senere.

Prosessene kan ses på som etnografiske eksempler på Eagleton og Mulherns argumenter mot Cultural Studies' muligheter og metoder for å forstå og inkludere "politikken”. Begge argumenterer for at Cultural Studies feiler ved å heve kultur over politikk, og derav definere samfunnets bevegelse fra humanisme til kultur til politikk, mens den egentlige bevegelsen er den andre veien: Fra politikk via kultur til humanisme. ${ }^{15}$ Senere vil vi se at Barenboim og Said forsøker nettopp å heve kulturen over politikken, blant annet ved å gjøre musikken til det fremste dialogverktøyet i orkesteret, mens orkestermusikerne nærmest automatisk inkluderer de betente politiske diskusjonene de bringer med seg fra hjemlandene sine. I den grad Barenboim og Said har inkludert politikk som en del av prosjektet er dette gjennom to forhåndsdefinerte «absolutter», som vi leser på orkesterets nettside:

«There is no military solution to the Israeli-Palestinian conflict.

The destinies of the Israeli and Palestinian people are inextricably linked and the land that some call Greater Israel and others Palestine is a land for two people.» ${ }^{16}$

Denne delvise tilbaketrekningen fra alt som kan synes politisk er interessant i lys av de teoriene Said var med på å bygge opp; for der Cultural Studies hever kulturen over politikken muliggjør postkolonialisme studien av kultur i lys den sosiale og politiske kontekst den opptrer i. Det kan dermed se ut til at det er en motsetning mellom Saids teorier og hans syn på den musikalske kanon. Dog - til tross for at rammene her ikke tillater en grundig analyse av dette - vil jeg påpeke til Saids forsvar at Said selv hevder det er lang fra presist å snakke om «vestlig kunstmusikk». For å bruke hans egne ord:

Selv om vi begrenser oss til «vestlig» klassisk musikk vil vi se at denne musikalske praksisen foregår på mange forskjellige steder, med forskjellige formål, for forskjellige publikumsgrupper og utøvere, og selvsagt på mange forskjellige tidspunkt. ${ }^{17}$

Said mener den vestlige klassiske musikken (kunstmusikken) har blitt globalisert, og dermed er den ikke et objekt for postkoloniale studier. Stokes påviser sammenhengen mellom globalisert musikk og kosmopolitisk musik ${ }^{18}-$ og som Thomas Hylland Eriksen og Halvor Finess Tretvoll påpeker: «Der det i dag er forskjeller, går kosmopolitikken ofte inn for universalisme». ${ }^{19}$

Før utviklingsprosessene introduseres vil jeg presentere hvordan vi kan forstå musikk som et middel for dialog og kommunikasjon innenfor konflikttransformasjonsteorier. Jeg velger her å bruke begrepet konflikttransformering fremfor konfliktløsning. Transformasjon er et mer presist begrep fordi det ikke bare fokuserer på løsning av et problem, men også hva som følger etter løsningen, det er med andre ord et begrep som favner bredere enn løsning gjør.

\section{Transformasjon gjennom musikk}

Divanorkesteret er etablert som et humanitært prosjekt. ${ }^{2 \circ}$ Hovedmålet er ikke å være et alternativt fredsprosjekt, men snarere å «se hva som skjer hvis du samler disse unge menneskene sammen for å spille i et orkester i Weimar». ${ }^{21}$ Til tross for denne upolitiske målsettingen stiller Barenboim 
og Said seg åpne for de potensielle politiske resultatene orkesteret kan ha. Som Said formulerer det:

Ingen skal undertegne noen erklcering. Det skal bare vare en underlig blanding med et slags kulturelt sentrum og en rekke uforutsette og mulige konsekvenser, som kanskje er politiske. Men ettersom ingen av oss er politikere, er vi egentlig ikke interessert $i$ den siden ved arrangementet. Det vi er interessert $i$, er musikkens, diskusjonens og kulturens makt til å skape en følelse av likeverd og slektskap som ellers er helt utilgjengelig $i$ all smerten og alle spenningene som preger det polariserte livet $i$ Midtøsten.22

Måten musikerne forholder seg til konflikten i Midtøsten på er med andre ord av en helt annen karakter enn politikernes måte. Som Barenboim beskriver: «Som orkestermusiker må man gjøre to ting på én gang, man må uttrykke seg, for å bidra til den musikalske helheten, og på samme tid må man lytte til de andre, for å forstå hva de gjør». Musikk kan forstås som et alternativ til verbal forhandling. Både Lederach og Galtung påpeker at det er musikkens makt som gjør den til et mulig middel i konflikttransformering, fordi musikken har styrke til å bevege mennesker og minner oss om vår felles menneskelighet. ${ }^{23}$ Forstått på denne måten kan musikken endre menneskers oppførsel. I følge Lederach har den artistiske eller musikalske prosessen mange likhetstrekk til forsoningsprosesser, ettersom den til syvende og sist går forbi det som kan bli rasjonelt forstått og analysert, for så å returnere til et sted eller en tilstand som tillater analyse og muliggiør meningsdannelse. I denne prosessen etableres alternative relasjoner - alternativ til relasjonene preget av problemer fra det virkelige liv. Musikk er altså en linse som tillater oss å se forbi de innledende problemene og heller fokusere på de dypere mønstrene av relasjoner, inkludert den konteksten konflikten uttrykkes i. Sett i lys av dette er essensen av dialogarbeidet i Divanorkesteret relasjonene som etableres gjennom musikalsk samhandling og musikken de spiller. De nye relasjonene kan etablere nye sosiale verdier og skaper sterk følelse av tilhørighet, fordi musikk bringer frem den sosiale dynamikken i en gruppe. Dette fører til at harmonier såvel som strandede relasjoner kommer til syne. ${ }^{24}$

\section{Empowermentprosess}

Divanmusikerne definerer seg i mellom en prosess som legger verdigrunnlaget for de nye relasjonene, og dem i mellom foregår det forhandlinger som leder frem til en «Divanrelasjon» og «Divanidentitet». Et spennende øyeblikk i feltarbeidet mitt var etter en av de offisielle kveldsdiskusjonene på workshopen. Den libanesiske forfatteren Elias Khouri (forfatter av blant annet «Yalo» og «Solens port») og den israelske forfatteren David Grossman (som blant annet har skrevet «Den indre grammatikkens bok» og «Den gule vinden») var invitert til å snakke om bøkene sine i lys av identitetsbegrepet og fremstilling av «den andre», under ledelse av litteraturprofessor Jaqueline Rose. Barenboim var ikke tilstede - det var fortsatt flere dager igjen til han skulle ankomme Pilas. Etter en lengre diskusjon mellom forfatterne, som konstant skiftet mellom å være en litteraturdiskusjon og en ren politisk debatt, åpnet Rose for spørsmål fra publikum. Til tross for

FOTO: (C) TOM FECHT, 2009 www.TOMFECHT.Сом 

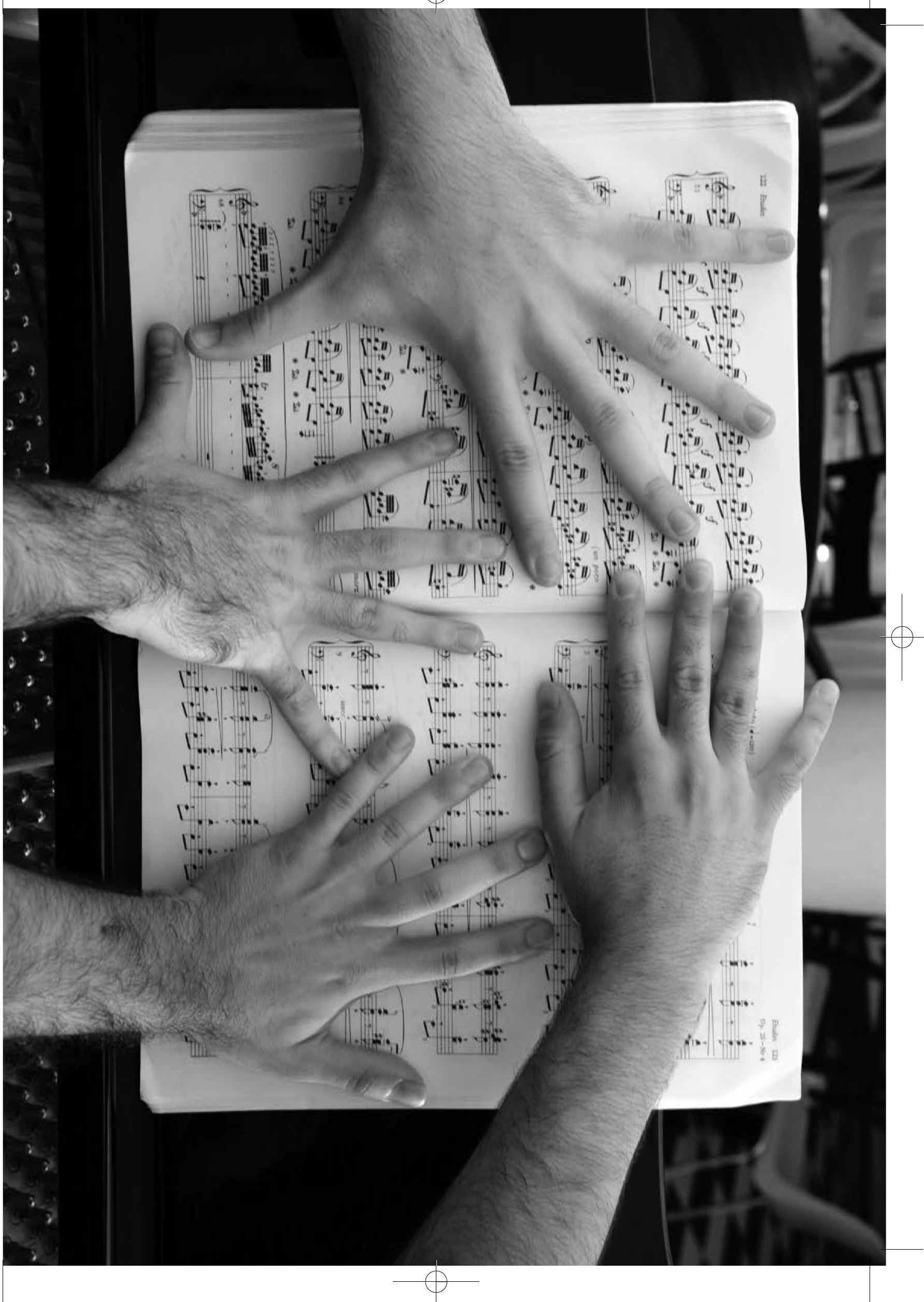
flere oppfordringer om å holde diskusjonen på et ikkepolitisk nivå så politikken ut til å være uunngåelig, både for forfatterne og musikerne. Det var spesielt en nykommer som ga en kommentar med klart politisk innhold, og hans kommentar førte til en langvarig diskusjon mellom musikerne på workshopen.

Først og fremst var vedkommendes kommentar en emosjonell utladning, et svært personlig, politisk og følelsesladet innlegg til debatten. Innpakket $i$ et spørsmål brukte nykommeren anledningen til å fortelle om sin opplevelse av situasjonen i Midtøsten, med stikkordene smerte og lidelse. Etter at diskusjonen var avsluttet ble jeg møtt av musikere fra samtlige representerte land som alle på hver sin måte fortalte hvordan de hadde opplevd diskusjonen. Flere forsøkte å moderere min fortolkning av situasjonen. Det var åpenbart et skille mellom nykommerne og de musikerne som hadde vært i Divanorkesteret i flere år. Representanter fra sistnevnte gruppe fortalte meg at nykommerens uttalelse bør forstås som innledende fase til en obligatorisk prosess for nykommere: «Det er noe alle må igjennom», sa de. Nykommeren selv fortalte meg noen dager senere om resultatene av hans uttalelser. Han hadde behov for å uttrykke de følelsene og erfaringene han hadde, og hadde «følt seg bedre etter at han hadde sagt det han sa», til tross for at det var emosjonelt krevende også etter diskusjonen; han hadde gått til rommet sitt, grått mye, men til slutt opplevde han det som en lettelse å ha gitt uttrykk for det han opplevde som personlige erfaringer og meninger.

Denne historien forteller om hvordan musikerne selv opplever hva slags prosess som finner sted i orkesteret. Det de beskrev for meg var en "empowering” eller opplærende prosess som går over flere år. Slik de forklarte den til meg gir denne prosessen musikerne styrke eller makt til å delta i en diskusjon preget av gjensidig toleranse og åpenhet, de blir "empowered". Ved først å opparbeide et skille mellom tanker og følelser - en emosjonell disiplin - blir musikerne i stand til å delta i og gjennomføre politiske diskusjoner. I Pilas var jeg blant annet vitne til to musikere som diskuterte alternative løsninger for fremtidens Jerusalem. Snarere enn å snakke om Jerusalem som den symbolsaken den ofte opptrer som, var disse musikerne konstruktive, kritiske og åpne, og ikke redde for å diskutere åpenbart betente politiske temaer.

\section{- eller kultiveringsprosess?}

Denne prosessen er imidlertid ikke så rent lite preget av Barenboim. Jeg forsto etter diskusjonen at flere musikere mente at nykommeren aldri ville fått anledning til å si det han sa om Barenboim hadde vært tilstede på diskusjonen. Jeg fikk også vite at Foundation i ettertid ga nykommeren munnkurv for fremtidige diskusjoner, ettersom de mente at uttalelser med så klart politisk uttrykk ikke passet seg i Divanorkesteret.

Her ser vi konturene av en intern maktstruktur, der det til syvende og sist er Barenboim som definerer utviklingsprosessen i Divan. Jeg vil betegne prosessen slik Barenboim definerer den som en kultiveringsprosess. Det er en prosess som kan minne om en klassisk dannelsesprosess, dog uten de politiske elementene dannelse direkte eller indirekte kan referere til. Musikerne kultiveres til en emosjonell disiplin ved å spille musikk sammen, under Baren- 


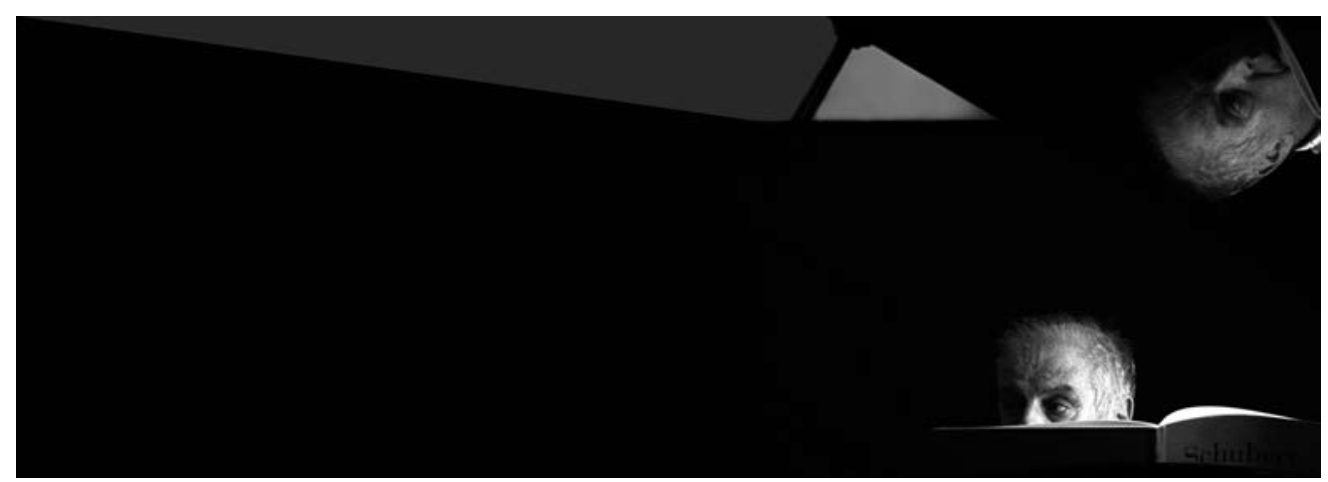

boims ledelse, og fremfor å gå inn i politiske diskusjoner (slik musikerne fortalte meg at de ønsket), legger Barenboim opp til at brorparten av forhandlingen og dialogen skal skje med musikk som virkemiddel.

Om bruk av musikk som politisk uttrykksform skriver Hennion følgende: «Music both helps a social entity to access reality, and prevents it from expressing itself through more political means».25 Hennions sitat er beskrivende for hvordan Barenboim definerer kultiveringsprosessen i Divan. Han kontrollerer diskusjonene i orkesteret, og er, som den musikalske lederen, den som til syvende og sist definerer det musikalske uttrykket. Det samme gjelder diskusjonene, ettersom flere Divanmusikere påpekte at Barenboim kontrollerer hvilke narrativer det er rom for i orkesteret. Ifølge flere israelske musikere er Barenboim en venstreorientert sympatisør og notorisk skeptisk til Israel, og gir med det lite rom for de israelske musikernes narrativer. Paradoksalt er det derfor at Barenboim presenterer narrativenes rolle i orkesteret på følgende måte: «I Divanorkesteret får musikerne mulighet til å uttrykke sitt eget narrativ, og på samme tid høre de andres narrativ». ${ }^{26}$ Hvilken verdi får narrativuttrykk i orkesteret hvis de begrenses eller kontrolleres av Barenboim?

\section{Hvem definerer?}

Det er en motsetning i hvordan musikkens rolle i dialogarbeidet i orkesteret forstås av musikerne på den ene siden og Barenboim på den andre. For mens musikerne mener at utviklingsprosessen primært foregår gjennom diskusjon, samtale og sosial samhandling, ser det ut til at Barenboim legger vekt på musikken. I sine BBC Reith Lectures fra 2006 hevder Barenboim at det er det «universelle, metafysiske språket musikk som knytter musikerne sammen, musikk er språket musikerne bruker i dialogarbeidet». ${ }^{27}$ Hvis musikk kan hindre sosiale grupperinger i å uttale seg i politisk forstand slik Hennion foreslår, kan det tenkes at Barenboim, ved å vektlegge musikken og ved å kontrollere debatten, ikke bare kontrollerer narrativene og utviklingsprosessene, men også definerer det politiske uttrykket?

I denne sammenheng må vi ta i betraktning at både Said og Barenboim og deres noe kosmopolitiskinspirerte verdigrunnlag er eksempler på den menneskelige effekt av globalisering. Barenboim ble født i Argentina, flyttet til Israel i en alder av ti år, 
og har i sitt voksne liv jobbet som sjefdirigent blant annet i Paris, Chicago og nå i Berlin. Han snakker syv språk (hebraisk, engelsk, italiensk, fransk, tysk, russisk og spansk, og på Divanworkshopen gikk det rykter om at han for tiden lærer seg arabisk). Barenboim har et musikalsk nedslagsfelt i verdensklasse. Med andre ord: Han er en sann kosmopolitt og postmodernist, en «identitetsshopper» som selv sier han føler seg hjemme der han kan spille musikk. Også Said kan betegnes som en kosmopolitt, selv skriver han at han har kommet til den slutningen at han foretrekker å være «på feil sted». ${ }^{28}$

Da Barenboim i begynnelsen av 2008 fikk palestinsk statsborgerskap (i tillegg til sitt argentinske, spanske og israelske) var vi vitne til en kosmopolitt som bruker nasjonalitet som en politisk uttrykksform snarere enn til identitetsbygging og tilhørighetsfornemmelse. I Barenboims kommentar til det doble statsborgerskapet leser vi at han har klare politiske meninger om situasjonen i Midtøsten, ${ }^{29}$ og det kan se ut til at han lar disse prege også grunnlaget for den dialogen som finner sted i Divanorkesteret. Dette gjelder ikke bare diskusjonene, men også musikkens rolle i orkesteret.

På Divanworkshopen opplevde jeg at musikernes idolisering av Barenboim tillater ham å definere og kontrollere de prosessene som foregår internt. I seg selv er det betydningsfullt for en ung musiker fra Midtøsten å kunne sette på sin CV at de har arbeidet med Barenboim - gitt hans høye anseelse i det internasjonale klassisk musikkmiliøet. Videre deler Foundation ut studiestipender til utvalgte, talentfulle musikere. Stipendene brukes til studier i utlandet, især i Tyskland. Stipendene er en av de få mulighetene musikerne har til å studere klassisk musikk på høyere nivå, gitt de mangelfulle studiemulighetene for dette i Midtøsten.

Barenboim har flere ganger beskrevet orkesteret som en «alternativ utopisk sosial republikk». ${ }^{30}$ Idolisering og til en viss grad avhengighet av Barenboim og Foundation muliggjør Barenboims kontroll av den utopiske republikken, og som vi vil se senere er han nasjonsbygger i denne utopien.

\section{Om definisjonsmakt: Wagner og Israel}

Den etterhvert så berømte fortellingen om Barenboims oppsetting av utdrag Wagners opera «Tristan og Isolde» $i$ Israel har fått sin arvtaker med Divanorkesteret. Det første først: Staten Israel har uformelt bannlyst Wagners musikk, da denne forstås som et symbol for grusomhetene fra tysk antisemittisme. Richard Wagner (I8I3-I883) var notorisk antisemitt, kjent som Hitlers favorittkomponist, og assosieres ofte med nettopp Nazi-regimet. Begrunnelsen for den israelske bannlysningen dreier seg om Wagners skrifter, om bruken av musikken, og om historiske hendelser rundt den. ${ }^{3}$

I juli 200I var Barenboim den første dirigenten som fremførte Wagner i Israel, til tross for massiv motstand. Barenboim hadde opprinnelig planlagt oppsetning av første akt av Wagners «Valkyrien», men ble bedt om å endre programmet. Programmet ble endret, men til alles overraskelse beholdt Barenboim Wagner på programmet som ekstranummer. Etter en lengre debatt i salen forut for ekstranummeret, der de som ønsket å forlate fikk anledning til det, fremførte Barenboim og Berliner Philharmoniker utdrag fra Wagners Tristan og Isolde. Som følge av fremføringen ble 
Barenboim boikottet i Israel, en boikott iscenesatt av kultur- og utdanningskomiteen i Knesset. ${ }^{32}$

Fem år senere spilte Divanorkesteret Wagner for første gang. I den forbindelse ble det gjennomført en votering blant de israelske Divanmedlemmene, og med én stemmes flertall vedtok musikerne at Wagner skulle spilles i Divanorkesteret. Her kan vi stille spørsmål ved hvorvidt vedtaket var basert på musikernes idolisering og avhengighet av Barenboim, eller om vedtaket faktisk gjenspeilte musikernes

\section{Musikk er en linse som tillater oss} å se forbi de innledende problemene og heller fokusere på de dypere mønstrene.

meninger. I 2008 var første akt av «Valkyrien» på programmet, men denne gangen ble det ikke gjennomført noen votering eller diskusjon forøvrig om hvorvidt orkesteret skulle tillate seg å spille Wagners musikk. Snarere ble vedtaket fra noen år tidligere ansett å være en endelig beslutning tatt på vegne av alle fremtidige israelske nykommere. Dette betyr imidlertid ikke at det var uproblematisk å oppføre Wagner i Divanorkesteret i 2008. Gjennom samtale med flere israelske musikere fant jeg at Wagneroppsettingen satte nasjonal identitet på dagsorden. Ved å spille Wagner tvinges de israelske musikerne til å ta et aktivt standpunkt til et av kjerneelementene i den dominerende kulturen i Israel: Ashkenazijødenes avstandstakning til germansk antisemittisme, og de tvinges til å velge mellom Barenboim og Divanorkest- eret på den ene siden, og israelsk kulturpolitikk på den andre.

I tråd med fortellingen om den emosjonelle nykommeren og musikernes egen idé om empowermentprosessen i Divanorkesteret er det nærliggende å snakke om en forhandling av sosial identitet i orkesteret. Jeg vil komme tilbake til dette, men nå er det verdt å stille spørsmål ved hvorvidt vi her er vitne til et orkester som inntar en konkurrerende posisjon til nasjonalstatene deltakerne kommer fra. Wagner-oppsetningen er med på å belyse dette spørsmålet, og leder an til det åpenbare oppfølgingsspørsmålet: Hvis det er konkurranse mellom orkesteret og nasjonalstaten, hvem av de to har sterkest definisjonsmakt? Når så mye makt er lagt bak den uformelle Wagner-bannlysningen i Israel, og Barenboim på den andre siden har vært så tydelig i sin mening om Wagner, er det ikke vanskelig å se for seg hvor utfordrende det må være for de israelske musikerne å ta standpunkt. Ved å motsette seg å fremføre Wagner i Divanorkesteret risikerer musikerne å gå glipp av muligheten til å få stipend fra Foundation. Dog, ved å fremføre Wagner opplever flere israelske musikere at de sviker hjemlandet sitt. Dette er et komplekst paradoks for orkesterets israelske musikere.

\section{Nasjonal identitet i konkurranse}

Historisk sett har man operert med to forskjellige definisjoner av et orkester, nemlig (I) en korporasjon av musikalske instrumentalister og (2) et korporativt musikkinstrument. ${ }^{33}$ Forskjellen på disse to definisjonene er enkelt sagt at den første refererer til orkesteret som institusjon, mens definisjon nummer to viser til orkesteret som et klingende «vesen». Den første av de 


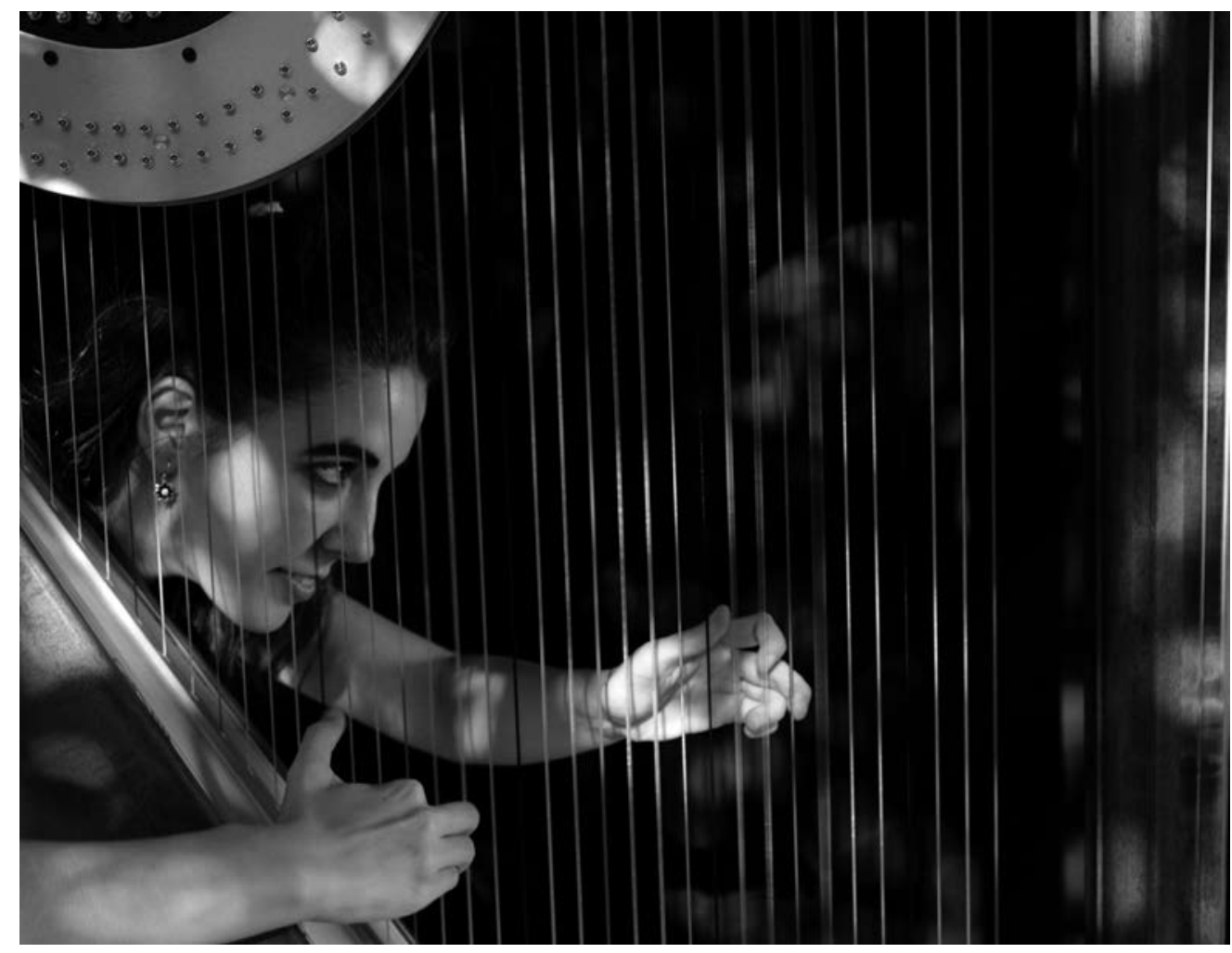

to, orkesteret som en institusjon knyttes ofte til metaforer som mikrokosmos eller sivilt samfunn, ${ }^{34}$ eller som Barenboim beskriver Divanorkesteret: en alternativ utopisk sosial republikk. Disse metaforene muliggjør utforskning av hvordan Divanmusikerne lever livene sine og spiller musikk sammen i orkesteret som om de var i et alternativt samfunn, og hva som kjennetegner identitetsdannelsen det alternative samfunnet tilrettelegger for.

I et orkester forstått som en institusjon må vi undersøke hva som skjer når mennesker spiller sammen, og som vi har sett tidligere er et av kjennetegnene for musikk i forsoningsarbeid det å bygge nye relasjoner. Barenboim formulerer det på denne måten:

I8 FAGFELLEVURDERT
There is automatically a common terrain on the music, because in front of the Beethoven symphony they are all equals. In real life they are not. 35

Gjennom musikk kan orkesteret, forstått som en institusjon, tilby Divanmusikerne et rom der alle er likeverdige, og der likeverdigheten tillater musikerne å uttrykke sine narrativer samtidig som de lytter til de andres narrativer. I tråd med argumentasjonen om at Divanorkesteret bidrar til etablering av nye relasjoner, vil jeg hevde at musikerne ikke bare gir uttrykk for egne og lytter til andres - narrativer. I tillegg etablerer de et felles narrativ basert på tilhørighet, felles erfaringer og nye vennskap i Divanorkesteret. Dermed bidrar musikk til å skape felles identitet for musikerne 
gjennom et symbolsk fellesskap. ${ }^{36}$ Basert på denne postkolonialistiske forståelsen av identitetsdannelse, der musikk forstås å ha en "formende" rolle i identitetskonstruksjon, finner vi at musikken er med på å skape ny identitet for Divanmusikerne. Gjennom musikalsk samhandling deltar alle $\mathrm{i}$ forhandlingen om et nytt, komplekst og nyansert narrativ de kan ha i fellesskap. Frith understreker hvordan musikk og kulturell aktivitet handler om å "leve ut en gruppes ideer":

[I]s not that social groups agree on values which are then expressed in their cultural activities (the assumption of the homology models), but that they only get to know themselves as groups (as a particular organization of individual and social interests, of sameness and difference) through cultural activity, through aesthetic judgment. Making music is not a way of expressing ideas; it is a way of living them. ${ }^{37}$

En sammenlikning mellom orkesteret som sivilt samfunn og Barenboim som statsleder er ikke urimelig om vi skal kunne avdekke hvem som har makt til å definere de ideene som leves ut gjennom musikalsk samhandling. Edensor skriver at i enhver stat vil statsmakten forsøke å kultivere sitt sivile samfunn:

This is done not least by the political state; in order for it to flourish it must inculcate in its citizens the proper sorts of spiritual disposition. [...] In a civil society, individuals live in a state of chronic antagonism, driven by opposing interests; but the state is that transcendent realm in which these divisions can be harmoniously reconciled. ${ }^{8}$
Det kan se ut til at Barenboims ideer, musikalske tanker og politiske verdier begrenser Divanmusikernes utviklingsmulighet. Musikerne er villige til å diskutere politiske temaer, med emosjonell disiplin som kriterium og grunnlag. Med Barenboim som det store idolet er denne utviklingen dog begrenset, ettersom den «rene» politikken er uønsket i Barenboims kultiveringsprosess. Snarere enn å oppmuntre til dialog der politikken inkluderes er Barenboim nasjonsbygger i en utopi fri for alt som kan synes politisk betent.

\section{Fra Midtøsten til Utopia}

Måten orkesteret er organisert på byr på flere problemstillinger. All den tid orkesteret opererer på en måte som muliggjør identitetsdannelse som kan synes konkurrerende med nasjonalstatene i Midtøsten står orkesterets ledelse ovenfor en alvorlig problemstilling, for hvordan skal disse musikerne kunne bringe tilbake sine opplevelser av dialog, samarbeid og felles verdier hvis Divanorkesteret til syvende og sist bare er et utopisk samfunn? Klarer de unge musikerne å se en parallell mellom Divanorkesteret og situasjonen i Midtøsten, og med det mane til dialog også på hjemmebane? Barenboim og Saids beslutning om å forbli «upolitiske» kan se ut til å bidra til en tilbaketrekning av prosjektet fra den opprinnelige konteksten det er tenkt å kommentere - Midtøsten - og erstatte den med en utopisk kontekst preget av universalisme og politisk fravær. Tilbaketrekningen muliggjøres ved å vektlegge kosmopolitiske verdier.

I Divanorkesteret er det flere forhandlinger som finner sted samtidig, og til sammen utgjør disse et komplekst system av sannheter og sammenhenger. Orkest- 
ermusikerne forhandler seg i mellom, returnerende musikere forhandler med nykommerne, og alle forhandler med Barenboim om hva slags prosess Divanorkesteret skal være. Orkesteret i sin helhet er i forhandling med nasjonalstatene, og Barenboim forhandler om kosmopolitisme versus nasjonalisme. Og dette er bare noen av de utallige forhandlingene som finner sted.

Barenboim og Said etablerte Divanorkesteret som et «humanitært prosjekt». I Said og Barenboims øyne er musikken et universelt språk, og Divanorkesteret en utopisk republikk. I lys av Eagleton og Mulherns teorier ser det ut som om Divanorkesteret er en tenkt utvikling fra humanisme til kultur - grunntaken er at musikk og kontrollert diskusjon gjør musikerne i stand til å uttrykke egne narrativ og samtidig lytte til andres. I sum skaper musikerne en felles kultur der det er plass til alle. Politikken, dog, ønsker Barenboim og Said å utelukke fra diskusjonene så langt det er mulig, og det som er av politisk uttrykk er i stor grad definert av Barenboim.

På den annen side bringer musikerne nærmest automatisk politikken med seg til orkesteret. Hadde musikerne hatt frihet til å definere og utføre den empowermentprosessen som de selv ønsker seg, ville vi muligens sett en bevegelse fra politikk via kultur til humanisme. Her ville det vært rom for relasjonsbygging basert på det virkelige liv snarere enn på utopien, og det nasjonale ville følgelig ikke nødvendigvis være i konkurranse med utopien eller kosmopolitismen. Det kan se ut til at Barenboims verdier og musikernes idolisering og avhengighet av ham er med på å forhandle orkesteret bort fra det konfliktfylte utgangspunktet for prosjektet: Bort fra
Midtøsten og inn i utopien. Da blir det problematisk å omtale Divanorkesteret som et konflikttransformerende prosjekt.

\section{$\cdot f \cdot$}

I URL: http://west-easterndivan.artists.warner.de. Lesedato 20.01.2007.

2 Fra 2002 har orkesteret blitt administrert av BarenboimSaid Foundation i Spania. Foundation mottar årlig en betydelig sum over Andalucias kulturbudsjettet, under forutsetning av at 30 prosent av musikerne er spanske.

3 Temaet er grundig behandlet i min masteroppgave. Riiser, Solveig: «Negotiating the Divan. A Study of the West-Eastern Divan Orchestra». Masteroppgave ved Institutt for Musikkvitenskap, Universitetet i Oslo, 2009.

4 New Oxford American Dictionary: «Negotiation». New York: Oxford University Press, 2008.

5 Se Lederach, John Paul: «The moral imagination: the art and soul of building peace». Oxford New York: Oxford University Press, 2005; Urbain, Olivier (red.) «Music and Conflict Transformation. Harmonies and Dissonances in Geopolitics.» London: I B Tauris \& Co Ltd, 2007.

6 Bourdieu, Pierre: «Distinction. A Social Critique of the Judgement of Taste». Mass.: Harvard University Press, I984.

7 Hylland Eriksen, Thomas og Finess Tretvoll, Halvor: «Kosmopolitikk. En optimistisk politikk for det 2I. århundre». Oslo: Cappelen Forlag, 2006.

8 Said, Edward W.: «Out of place. A memoir». London: Granta, I999.; Said, Edward W.: «Reflections on exile and other literary and cultural Essays». London: Granta, 200I.; Barenboim, Daniel: «A life in music». New York: Arcade Publishing, [I99I] 2002.

9 Dette er også et krav for å kunne bli med i orkesteret. I «Call for Applications 2008» leser vi følgende krav om nasjonal tilhørighet: «[...] To be a national or have a back ground of any of the Arab countries of the Middle East (Egypt, Jordan, Palestine, Lebanon, Syria, etc.), Israel or Spain. By background we mean that any of their blood relatives, up to second degree, are passport holders of any of the aforementioned countries.» URL: http://www.barenboim-said.org/index.php?id=I9O. Lesedato: 28.02 .2008 .

Io Edensor, Tim: «National Identity, Popular Culture and Everyday Life» New York: Berg, 2002.

II Ruud, Even: «Musikk og identitet.» Oslo: Universitetsforlaget, 2007.

I2 Hawkins, Stan: «Settling the Pop Score. Pop texts and identity politics». Aldershot: Ashgate, 2002.

I3 Attali, Jacques: «Noise. The Political economy of music». Minneapolis: University of Minnesota Press, [1985] 2006.; Siepmann, Jeremy: «The history of direction and conducting» i Lawson, Collin (red.): «The Cambridge companion to the orchestra». Cambridge: Cambridge 
University Press, 2003.

I4 New Oxford American Dictionary: «Empowerment». New York: Oxford University Press, 2008. For musikkterapeutisk bruk av begrepet, se for eksempel Pavlicevic, Mercedes og Ansdell, Gary (red.): «Community Music Therapy». London: Jessica Kingsley Publishers, 2006.

I5 Mulhern, Francis: «Culture/Metaculture». London: Routledge, 2000.; Eagleton, Terry: «The idea of Culture». Oxford: Blackwell Publishing, 2000.

I6 URL: http://west-easterndivan.artists.warner.de Lesedato: 20.01.2007.

I7 Said, Edward W.: «Musical elaborations». New York: Columbia University Press, I99I.

I8 Stokes, Martin: «On Musical Cosmopolitanism». Innlegg presentert på «Institute for Global Citizenship, The Macalester International Roundtable», 2007. URL: http://digitalcommons.macalester.edu/intlrdtable/3. Lesedato: 09.0I.2008.

I9 Hylland Eriksen, Thomas og Finess Tretvoll, Halvor: «Kosmopolitikk. En optimistisk politikk for det 2I. Århundre». Oslo: Cappelen Forlag, 2006.

20 URL: http://west-easterndivan.artists.warner.de Lesedato: 20.01.2007.

2I Barenboim, Daniel og Said, Edward W.: «Parallels and Paradoxes». London: Bloomsbury Publishing Plc., 2003.

22 Said, Edward W. og Barsamian, David: «Kultur og motstand. David Barsamian. I samtale med Edward W. Said». Oslo: Forlaget Oktober, 2003. Merk: sitatet er fra et intervju gjort forut for West-Eastern Divans oppstart i Weimar i 1999.

23 Lederach, John Paul: «The moral imagination: the art and soul of building peace». Oxford New York: Oxford University Press, 2005.; Galtung, Johan: « Peace, Music and the Arts: In Search of Interconnections». i Urbain, Olivier (red.): «Music and Conflict Transformation. Harmonies and Dissonances in Geopolitics». London: I B Tauris \& Co Ltd, 2007 .

24 Jandt, Fred E.: «An introduction to intercultural communication. Identities in a global community». Thousand Oaks, Calif: Sage Publications, 2007.

25 Hennion, Antoine: «Music and Mediation. Towards a new sociology of music» i Clayton, Martin; Herbert, Trevor og Middleton, Richard: «The Cultural study of music. A critical introduction». New York: Routledge, 2003.

26 Barenboim, Daniel: «BBC Radio Reith Lectures». URL: http://www.bbc.co.uk/radio4/reith2006/ 2006. Lesedato: 23.02 .2008 .

27 Barenboim, Daniel: «BBC Radio Reith Lectures». URL: http://www.bbc.co.uk/radio4/reith2006/ 2006. Lesedato: 23.02 .2008 .

28 Said, Edward W.: «Out of place. A memoir». London: Granta, I999.; Barenboim, Daniel og Said, Edward W.: «Parallels and Paradoxes». London: Bloomsbury Publishing Plc., 2003.
29 Barenboim, Daniel: «Dual citizenship». URL: http://www.danielbarenboim.com/journal_ acceptance2.htm 2008. Lesedato: 03.09.2008.

30 Se for eksempel Barenboim, Daniel: «BBC Radio Reith Lectures». URL: http://www.bbc.co.uk/radio4/reith 2006/ 2006. Lesedato: 23.02.2008.

3I Se Guldbrandsen, Erling E.: «Den ustanselige aktualitet: Richard Wagner i Bayreuth I998». URL: http://www.wagneropera.no/Artikler/EEGDen UstanseligeAktualitet-I998.htm. Lesedato: I6.0I.2009.

32 Knesset-resolusjon, 25.07.200I. Sitert i Barenboim, Daniel og Said, Edward W.: «Parallels and Paradoxes». London: Bloomsbury Publishing Plc., 2003.

33 Carter, Tim og Levi, Erik: «The history of the orchestra». I Lawson, Collin (red.): «The Cambridge companion to the orchestra». Cambridge: Cambridge University Press, 2003 .

34 «Mikrokosmos»: Gillinson, Clive og Vaughan, Jonathan: «The life of an orchestral musician». I Lawson, Collin (red.): «The Cambridge companion to the orchestra». Cambridge: Cambridge University Press, 2003.; «Sivilt samfunn»: Spizer, John og Zaslaw, Neal: «The Birth of the Orchestra. History of an institution, I650-1815». New York: Oxford University Press, 2004.

35 Barenboim, Daniel: «BBC Radio Reith Lectures». URL: http://www.bbc.co.uk/radio4/reith2006/ 2006. Lesedato: 23.02 .2008

36 Se Bennett, Andy: «Music, Space and Place». I Whitely, Sheila; Bennett, Andy og Hawkins, Stan (red.): «Music, Space and Place. Popular Music and Cultural Identity». Aldershot: Ashgate, 2004.

37 Frith, Simon: «Music and identity». I Hall, Stuart og du Gay, Paul (red.): «Questions of cultural identity». London: Sage Publications, I996.

38 Edensor, Tim: «National Identity, Popular Culture and Everyday Life» New York: Berg, 2002. 